\title{
Getting Carried Away: Evaluating the Emotional Influence of Fiction Film
}

\begin{abstract}
Stacie Friend
(Please only cite the published version of this paper, in Midwest Studies in Philosophy XXXIV: Film and the Emotions, edited by Peter French and Howard Wettstein. Wiley-Blackwell 2010)
\end{abstract}

It is widely taken for granted that fictions, including both literature and film, influence our attitudes toward real people, events, and situations. Philosophers who defend claims about the cognitive value of fiction view this influence in a positive light, while others worry about the potential moral danger of fiction. Marketers hope that visual and aural references to their products in movies will have an effect on people's buying patterns. Psychologists study the persuasive impact of media. Educational books and films are created in the hopes of guiding children's and adult's preferences toward socially acceptable norms. The influences discussed by marketers, psychologists, educators, and philosophers tend to be both cognitive and affective. It seems that we can be "emotionally persuaded": our preferences can be changed, our feelings about particular people or events can be influenced, and so forth.

It takes but a little reflection, however, to motivate concern about these kinds of influences, not just their potentially negative effects, but the processes by which these effects occur. If we are persuaded by fictions, how can the resulting beliefs or preferences or attitudes be warranted? It would be implausibly extreme to think that acquiring beliefs or attitudes from fiction is always a mistake. So when is it appropriate? I have argued elsewhere for an approach to this question concerning the justification of beliefs acquired through fictions (Friend 2006). Here I would like to take up the issue of warrant for emotional responses.

The traditional discussion in this domain centers on the so-called Paradox of Fiction. As originally formulated by Colin Radford (1975), this is the puzzle of explaining how we can rationally experience emotions concerning the fictional, particularly people who do not exist or events that did not occur. Motivated by Kendall Walton's (1978) provocative answer - that we do not experience genuine emotions in fictional contexts - the debate has focused primarily on the problem of how it is possible to have emotions toward the fictional. I will largely ignore this debate here. The more interesting question is the rationality or appropriateness of these responses. ${ }^{1}$ Most philosophers, including Walton, agree that engagement with fiction can make certain emotional responses — whether or not these are classified as genuine 'emotions'-appropriate. I want to focus on what happens when we turn from the engagement context to what we may call the real-world context. ${ }^{2}$ That is, what happens when we move from responding emotionally to characters, situations, and events as depicted in a fiction (which can occur not only while watching a film or reading a book, but also when reflecting on fictional content later); to allowing those emotional responses to affect our feelings toward people, situations, and events as they are, or as we take them to be, in reality? Anyone concerned to explain how emotions in general can be appropriate or inappropriate should be concerned with this question. For it is not clear how or when the mechanisms by which fictions influence us affectively result in warranted emotional responses. This is particularly important when we consider that some approaches to the cognitive and ethical value of fiction assume that affective influences can

\footnotetext{
${ }^{1}$ Surprisingly little attention has been paid to this question. Exceptions include Livingston and Mele 1997 and Gaut 2003 and 2007, Ch. 9.

${ }^{2}$ Gaut (2003; 2007, Ch. 9) draws a distinction in criteria of warrant between emotions that involve imagining and emotions that involve believing. However, this distinction does not take into account belief-involving emotions invited by a fiction as part of engagement, which are particularly relevant for carryover.
} 
educate us to respond appropriately in real situations. If that is right, the fiction must somehow provide a warrant for the emotional responses it engenders, including a warrant for applying these responses to the relevant real-world circumstances.

In this paper I offer an account of warrant for emotions that "carry over" from the engagement context to the real-world context. The challenge for such an account is the apparent gap between conditions of warrant in the two contexts. For instance, even if a work makes pitying a fictional character appropriate, that does not appear sufficient by itself to justify pity of any real person. I argue, however, that for what I call the standard scenario, if a particular emotion in the engagement context - such as pity of a fictional character - is warranted, the emotion carried over into the realworld context - such as pity of a real person - is ipso facto also warranted. In the standard scenario, carryover is prompted by the assumption that the fiction is accurate in emotionally relevant respects. If the fiction meets the appropriate expectations of accuracy, emotions are warranted in either context. The gap closes.

In §1 I get clear about the phenomenon of emotional carryover. In the following two sections I propose accounts of warrant for emotions in the real-world context and the engagement context. I describe the standard scenario in more detail in $\S 4$. In $\$ 5$ I examine two films, JFK and The Hurt Locker, arguing that to the extent that they fail to meet appropriate expectations of accuracy, certain emotions in both contexts are unwarranted. Finally I address objections to this argument.

\section{Emotional Carryover}

Fictions can have real-world affective influences in a wide variety of ways, many of which are too diffuse or indirect to raise issues of appropriateness or warrant. To focus the discussion, it is necessary to circumscribe the relevant sort of affect as well as the relevant kind of influence.

My target is intentional affective states or processes: that is, affective states or processes directed at objects, whether or not these objects exist. I will call these emotions. I assume that emotions as defined always involve an evaluation of the object. According to cognitivists about emotion, the evaluation may be a belief or other propositional attitude concerning the object, for instance in fear that the object is dangerous. ${ }^{3}$ According to non-cognitivists it could be a "non-cognitive" or "embodied" appraisal, registering the presence of danger more directly (Robinson 2005; Prinz 2004, respectively). I intend my discussion to be neutral among competing theories of emotion. Thus my use of the term 'emotion' is stipulative in the sense that I am not arguing for a position on the nature of emotion; but it is not arbitrary because the issues of warrant that I consider apply fairly precisely to emotions as so defined. As a result, the phenomena I discuss will include states or processes that do not count as emotions according to at least some theories. For instance, I include affective responses to what is imagined, as well as responses that arguably do not involve propositional attitudes of any sort; cognitivists of various stripes would not include one or the other of these in the domain of emotions proper. $^{4}$ And I include affective responses that might persist over time, though a number of theorists restrict emotions to episodes that last only seconds or minutes (e.g., Ekman 1994). At the same time, I exclude certain phenomena from the present discussion. For instance, those who do not take intentionality to be a defining feature of emotion may include responses to affect-inducing drugs in this category (e.g., Prinz 2004, 29). Less controversially, I exclude moods, thought of as objectless affective states, or whose object is "the whole world."

\footnotetext{
${ }^{3}$ Whereas cognitivist philosophers distinguish instances of an emotion type by the specific propositional attitude involved, psychologists who defend cognitivism about the emotions (e.g., Lazarus 1991) tend to associate all emotions of a given type with specified sets of "cognitive appraisals" triggered in any instance. The differences between these approaches are not important for present purposes.

${ }^{4}$ Including the present author in Friend 2003. I still think that there are reasons to distinguish between emotions that involve imagining and emotions that involve believing, but these are not relevant to the present argument.
} 
The particular kind of affective influence that interests me here is one I call emotional carryover. Roughly, emotional carryover occurs when an emotion generated in the engagement context, directed at a particular object, leads to an emotion of the same type (anger, sadness, etc.) in the real-world context, directed at the same or a similar object. ${ }^{5}$ Start with the simplest case, taking emotions directed at persons as the example. Suppose you see a film in which a real person (not a made-up fictional character) is portrayed as suffering, and you respond in the context of engagement with pity. The emotion carries over if you continue to pity that person in the non-filmic context. Other cases of carryover are less direct, as when pity of a fictional character based on a real person carries over to pity of the real person; or pity of a character in fiction carries over to pity of real people who are similar to the character. I take it that the phenomenon of emotional carryover is familiar. For example, in the debate over the Paradox of Fiction, one solution sometimes broached is that our sympathy for, say, Anna Karenina is really sympathy for real women in similar situations. ${ }^{6}$ Although this proposal is widely and correctly rejected as a solution to the puzzle, no one denies that our experience of Tolstoy's novel can carry over in the way suggested. Similarly, The Hurt Locker (Kathryn Bigelow, 2009) was hailed by critics as providing audiences with an emotionally charged experience of what it is like for American soldiers serving in Iraq. With respect to films about particular individuals, it seems entirely natural that after seeing Terry George's Hotel Rwanda (2005), people admire Paul Rusesabagina (played in the film by Don Cheadle), the real hotel manager who risked his life to save Tutsis from the Rwandan genocide. Certainly William Randolph Hearst was in no doubt that attitudes toward the title character in Orson Welles's Citizen Kane (1941) would carry over to him.

Although emotional carryover has not been a topic of philosophical discussion, philosophers who claim that fiction can educate our emotions often seem to assume that the process involves carryover. For instance, Amélie Rorty says that for Aristotle, engagement with tragedy contributes to the virtues insofar as it helps instill "the capacity to have the right emotional reactions at the right time, in the right way, directed to the right objects" $(1992,12)$. Ronald de Sousa, who also appeals to Aristotle on moral education, claims that we learn appropriate emotional responses via exposure to paradigm scenarios, which "involve two aspects: first, a situation type providing the characteristic objects of the specific emotion-type ..., and second, a set of characteristic or 'normal' responses to the situation ..." $(1987,182)$. De Sousa goes on to say that fiction supplements real life in providing a greater variety of paradigm scenarios. ${ }^{7}$ Presumably the idea is that insofar as we respond in an appropriate way to fictional scenarios, we will go on to respond in the same appropriate ways to realworld scenarios that are relevantly similar to the fictional ones.

One might wonder whether anything is, literally speaking, "carried over" in such cases. If emotions are individuated at least in part by their objects, then in any instance where the emotion in the

\footnotetext{
${ }^{5}$ This characterization will be refined below, but it is already sufficient to contrast emotional carryover with two other phenomena with which it might be confused: excitation (or arousal) transfer and emotional contagion. Excitation transfer occurs when the arousal caused by one stimulus contributes to the intensity of an emotion in response to another stimulus (see Zillmann 1996). By contrast with emotional carryover, what is transferred is arousal only; the cause of the arousal need not be an emotion (it can, for example, be physical exercise), and even where it is, the emotions involved need not be of the same type. Emotional contagion occurs when we "catch" another person's mood or emotion as a result of automatically mimicking facial expressions, movements, and so on (Hatfield et al. 1992). In film, emotional contagion is a species of identification with a character that occurs simultaneously with viewing (see Coplan 1996 for an overview). Emotional contagion can generate emotional carryover, but only if the emotion that results from identifying with a character's emotions leads one to direct the same type of emotion toward the real world. Thanks to Matthew Kieran and Paloma Atencia-Linares for drawing my attention to these phenomena.

${ }^{6}$ This view is proposed in, e.g., Weston 1975, Paskins 1977, and McCormick 1985.

${ }^{7}$ De Sousa's subject is literature, but there is no reason his claims would not apply equally to film.
} 
engagement context (henceforth: EC) is directed toward a fictional character while the emotion in the real-world context (henceforth: RWC) is directed toward a real person or persons, whatever is carried over does not seem to be the same emotion. Having the same object does not guarantee sameness of emotion either. On a cognitivist theory according to which propositional attitudes are partly constitutive of an emotion, an emotion that involves imagining something about a particular individual will be distinct from an emotion that involves believing something about that individual. Similarly, theories of emotion according to which motivational role or action tendencies are essential will distinguish emotions in the two contexts. As is frequently noted, fear of fictions does not typically cause us to react in the same way as we would if confronted by similar real threats. Conversely, at least some people are more likely to cry during a sad movie than when faced with genuine misery, if there are pressures to remain stoic in the latter case (a point made by Plato some time ago).

To accommodate these considerations, I suggest the following characterization of emotional carryover. Emotional carryover occurs when:

at least part of the explanation of an emotion $\mathrm{E}$ of a given type (sadness, anger, etc.) occurring in the RWC is that an emotion E' of the same type was generated in the $\mathrm{EC} ;{ }^{8}$ and

ii) the explanation in (i) essentially appeals to the fact that the (intentional) object of E is taken to be the same or similar to the (intentional) object of $\mathrm{E}^{\prime}$. 9

With this in mind, we can reformulate the question above as: Can works of fiction warrant the carryover of emotions from the EC to the RWC, and if so, how? I will address this question specifically for our engagement with cinema, which offers a wider array of means for affective influence than literature.

\section{Warrant in the Real-World Context}

In order to see whether carryover is warranted, we first require an account of emotional warrant for both the real-world and engagement contexts. I begin with the former.

Let us take a warranted emotion to be one that is "an appropriate response to the evoking stimuli" (Livingston and Mele 1997, 159). Fear is appropriate in a dangerous situation, anger is appropriate when one has been harmed intentionally, and so on. Warrant is an epistemic notion, to be contrasted with other ways in which an emotion can be appropriate, for instance in terms of instrumental or moral value. It might be useful to get angry in a given situation - it could be the most efficient way to achieve one's goals - even if the anger is unwarranted. Conversely, it might be morally praiseworthy to resist anger even when it is clearly warranted. I will ignore these other kinds of appropriateness here. With that in mind, I distinguish three ways of assessing emotional warrant, defined for the RWC as follows:

(F) Fittingness: The emotion type is appropriate to one's real-world evaluation of the object of emotion.

(J) Justification: The emotion is fitting and the evaluation is epistemically adequate.

(C) Correctness: The emotion is fitting and the evaluation accurately represents genuine properties of the object of emotion.

\footnotetext{
${ }^{8}$ As will become clear below, E need not be distinct from E'.

${ }^{9} \mathrm{I}$ will focus on cases where the object of $\mathrm{E}$ is real. However, this is not necessary for carryover: if a viewer mistakenly believes a fictional character to exist, she might carry over emotions toward that character.
} 
Call these the real-world conditions of warrant, or $R W$-conditions for short. I will claim that an emotion in the RWC is fully warranted if and only if it meets all three conditions. Since an emotion cannot be justified or correct without being fitting, I begin with this criterion.

At issue in fittingness is whether the emotion type fits its formal object, the second-order property ascribed to the object of the emotion that provides the standard of correctness for normal occurrences of that emotion: fear for danger, pity for undeserved suffering, and so on. ${ }^{10}$ A real-world evaluation is an evaluation that is sensitive to the properties of the object as one takes it to be in reality. For cognitivists, the relevant real-world evaluation would be a belief concerning the object's genuine properties (as opposed, e.g., to an imagining prescribed by a fiction). For non-cognitivists, it would be an appraisal that registers properties of the object it is taken to have in reality (as opposed, e.g., to one that registers the properties a fiction presents it as having). Emotions can be fitting even if the associated evaluations are incorrect and/or unjustified. If I believe that a friend stole my money, anger is fitting in this sense even if my belief is false and even if my "evidence" is from a dream. Fittingness is often taken to be a minimal requirement for the rationality of an emotion. ${ }^{11} \mathrm{I}$ treat it as a component of the two other ways of assessing warrant.

A justified emotion is not only fitting, but also involves an evaluation that is epistemically adequate. What makes an evaluation epistemically adequate will turn on one's particular theory of justification or epistemic responsibility, and I do not take a stand here. I do want to make two remarks, however. First, epistemic adequacy is not all-or-nothing. Not only is justification or epistemic responsibility a matter of degree, what counts as epistemic adequacy for the purposes of justifying emotion may differ from one situation to another. If I see a friend take my wallet, I am justified in being angry without further ado. If I cannot find my wallet and then see my friend looking uncomfortable, more evidence would be required to justify anger. In either case the question of justification is independent of correctness. What I justifiably interpret as theft might turn out to be something else altogether. Indeed there are good reasons to think that emotions are often responsive to incomplete or partial evidence (see Greenspan 1988). One might be justified in evaluating a situation as dangerous given certain cues even while possessing conflicting evidence, resulting in mixed feelings. The second point is that questions of epistemic adequacy are not restricted to cognitive theories of emotion. For one thing, automatic appraisals can be more or less sensitive to available information, just as perceptual processes can be more or less reliable. But even if we take justification to pertain primarily to cognitive processes, the debate between cognitivists and non-cognitivists concerns the trigger of emotion, not its justification. Non-cognitivists argue that emotions can be initiated by stimuli that directly affect the amygdala, prompting an affective response prior to any signal's being sent to cognitive (cortical) areas of the brain (e.g., Zajonc 1980; LeDoux 1994, 1996). This is by contrast with cognitivists who do not count an affective state as an emotion until cognition is involved. But even the most fervent non-cognitivists will agree that cognition plays a role in the development of an emotion. ${ }^{12}$ If I react automatically with a fear response to a coiled rope seen out of the corner of my eye due to an automatic evaluation of threat prompted by anything snake-like, there might not be much to say about whether or not this reaction is justified. But once having had an opportunity to examine the rope, a failure to adjust my evaluation would surely be up for epistemic criticism.

Finally, an emotion can be assessed as correct or incorrect. A fitting emotion is correct so long as the associated evaluation accurately represents genuine properties of the object of emotion. Where the evaluation is a belief the criterion is fairly straightforward: if the belief that someone has suffered

\footnotetext{
${ }^{10}$ This use of the term 'fitting' originates in Broad 1954.

${ }^{11}$ To be fitting an emotion must also be of an intensity proportionate to the evaluation. For ease of exposition I ignore this issue here.

${ }^{12}$ See, for example, Robinson's (2005) discussion of “cognitive monitoring," which relies on LeDoux 1996.
} 
undeservedly is true - the object of pity really has suffered undeservedly — pity of that person is correct, otherwise not. If an emotion is responsive to, say, a perceptual cue that does not (yet) figure in a full-fledged belief, it will still be correct so long as the cue registers a real feature of the object.

Again, correctness is independent of justification. If a person who has always been reliable in the past informs me that a mutual friend is seriously unwell, my pity is justified; but if she is in fact not ill, it is an incorrect response. Conversely, someone who perceives all dogs, even the gentlest, as dangerous, will occasionally fear a dangerous one correctly, even if she lacks justification.

In my terminology, an emotion is fully warranted if and only if it is both justified and correct, where each of these conditions includes fittingness. ${ }^{13}$ It is not uncommon to treat the terms justification and warrant as synonyms, and I stake little on the choice of words. My aim in including correctness is to capture the sense in which an emotion is inappropriate insofar as it is not deserved by its object. If I am angry at Anthony for revealing my secrets, then no matter how justified I am in this anger, Anthony does not deserve it if he did not reveal my secrets. In that case, it is natural to say that the situation does not warrant anger.

\section{Warrant in the Engagement Context}

Even if we agree that emotions in the EC are no different in kind from emotions in the RWC, there do appear to be differences in how they are warranted. To see why, it is useful to begin with Paisley Livingston and Alfred Mele's (1997) thoughtful account of congruence for emotional responses to fiction. ${ }^{14}$ Livingston and Mele adopt a cognitivist account according to which the evaluations involved in emotions in response to fiction are beliefs, specifically beliefs about what is true in a work (161). On this account, congruent emotions are those that are based on fictional truths. Fictional truths may be explicitly stated or presented, as when we see Carlo Rizzi (Gianni Russo) beat up his pregnant wife Connie (Talia Shire) in The Godfather (Francis Ford Coppola, 1972). Or they may be implicit, as when we infer from events that Michael Corleone (Al Pacino) is responsible for Carlo's murder. If we pity Connie, have contempt for Carlo, and experience a growing sense of dread at Michael's coldness, these emotions will be congruent with what is fictionally true in The Godfather. Jaded amusement or elation, by contrast, would be incongruent responses. The motivating idea is that our emotional responses to fiction by and large follow our emotional responses to real life: if anger is an appropriate response to (real) intentional harm, then anger-presumably with attenuated intensity and action tendencies - is a congruent response to fictional intentional harm. Congruence so understood appears to incorporate a version of fittingness, where for Livingston and Mele the fit is with a belief about what is fictionally true; and a version of correctness, which on their account requires that the belief accurately represent the fictional truth.

Fittingness and correctness are not the only dimensions of warrant, however, even in the EC. For most of Memento (Christopher Nolan, 2000) the viewer is supposed to feel sorry for the main character, Leonard (Guy Pearce), whose attempts to find his wife's murderer are constantly thwarted by his inability to form short-term memories. But what is fictionally true, as the audience discovers late in the film, is that Leonard is the one who killed his wife and then manipulates situations so that he can murder new "suspects" again and again. Given this fictional truth, pity of Leonard before this discovery is incorrect; but it is surely justified. Although they are not entirely clear on the subject, Livingston and Mele (1997) seem to want congruence to cover not only correctness but also justification. They point out in criticizing Currie that many responses might be appropriate only locally, given the evidence one has up to that point in experiencing the fiction, rather than globally

\footnotetext{
${ }^{13}$ Because there are degrees of justification, there will be degrees of warrant. For ease of exposition I will assume that emotions are warranted so long as they meet minimum standards of justification, otherwise not. ${ }^{14}$ The term congruence comes from Currie (1990, 213). Livingston and Mele (1997) take Currie's account of congruence as their starting point.
} 
(165). And they allow that congruence can attach to particular features of a work rather than the whole (174). Livingston and Mele could therefore say that an emotion in response to fiction is justified so long as it involves a belief that is reasonable in light of the evidence one has about the fictional truth at a given point in experiencing the fiction. A fitting emotion would be congruent so long as it is both correct (with respect to fictional truths) and justified (with respect to evidence for fictional truth).

Livingston and Mele's account of congruence captures key features of warrant in engagement with fiction. However, it will be useful to formulate the justification and correctness conditions in a way that does not require accepting that emotions in response to fiction necessarily involve beliefs concerning what is fictionally true. A more plausible brand of cognitivism holds that such emotions involve imaginings; moreover, we would like an account consistent with non-cognitivism. I propose the following conditions of warrant for the EC, or EC-conditions:

(F') Fittingness: The emotion type is appropriate to one's engaged evaluation of the object of emotion.

( $\mathrm{J}$ ') Justification: The emotion is fitting and the evaluation is fictionally adequate.

(C') Correctness: The emotion is fitting and the evaluation accurately represents fictional properties of the object of emotion.

A fitting emotion is one that is appropriate to an engaged evaluation, that is, one that occurs as part of engagement with a film and is typically directed, not to the properties possessed by the object of the emotion in reality, but to the properties the object possesses according to the fiction. For most cognitivists, the relevant kind of evaluation would be an imagining prescribed by the fiction; for a noncognitivist, it would an appraisal responsive to cues from the fiction. An evaluation is fictionally adequate so long as it is reasonable in light of the fictional information about the object of emotion available at the time. Whereas the nature of epistemic adequacy turns on one's theory of justification or epistemic responsibility, the nature of fictional adequacy turns on one's account of the "principles of generation" (Walton 1990, Ch. 4) for determining truth-in-fiction or, more broadly, the features of a depicted fictional world. Fictionally adequate evaluations reflect an audience's competence at deploying the appropriate principles given the fictional input, even if it turns out that these evaluations are incorrect. Finally, an evaluation meets the correctness condition, either if it is a propositional attitude (e.g., an imagining) that is fictionally true, or if it is a non-cognitive evaluation that accurately registers the properties the object has according to the fiction. Correctness is once again independent of justification. If my imagining that Michael Corleone is responsible for Carlo's death is the result of a wild guess (I've slept through half the movie), it will be correct without being justified.

As should be apparent, the EC-conditions so far elaborated parallel the RW-conditions. There may be additional considerations relevant to warrant for works of fiction as well as nonfiction that do not apply in the RWC, such as whether or not the work meets certain artistic standards. I will return to these in $\S 7$. For the present, the contrast between $(\mathrm{F}),(\mathrm{J})$ and $(\mathrm{C})$ on the one hand, and $\left(\mathrm{F}^{\prime}\right),\left(\mathrm{J}^{\prime}\right)$ and $\left(C^{\prime}\right)$ on the other, is enough to generate concern about emotional carryover. Engaged evaluations are not real-world evaluations; fictional adequacy is not epistemic adequacy. So what would warrant carrying over emotions from the one context to the other?

The challenge is best clarified by example. Consider JFK, Oliver Stone's 1991 film about the assassination of John F. Kennedy. ${ }^{15}$ In the movie Kevin Costner plays Jim Garrison, the real New Orleans District Attorney who prosecuted the only trial related to the assassination and whose book $O n$ the Trail of the Assassins (1988) was one of Stone's primary sources. According to both the book and the film, Lee Harvey Oswald (played in the film by Gary Oldman) was just a patsy in a military-

\footnotetext{
${ }^{15}$ I discuss $J F K$ in some detail in Friend 2003. However, my interpretation of responses to the film in the present paper departs from the analysis offered there.
} 
industrial-governmental conspiracy, reaching up to Vice President Lyndon Johnson, to assassinate Kennedy. In the movie as well as in reality, Garrison brought a New Orleans civic leader, Clay Shaw (Tommy Lee Jones), to trial in 1969 for being a part of this conspiracy. The film leaves no doubt about how we should feel about the events and people depicted. The film invites us to admire Garrison for his noble pursuit of the truth in the face of powerful foes; to fear for him and his family when they are threatened by the conspirators; to root for his success and to be disappointed when he fails to get a conviction. It invites us to have contempt for Shaw's arrogance and shady dealings; to be disturbed, possibly disgusted, by his sleazy lifestyle; to hope that he is convicted and disappointed when he is not.

Let us suppose for the moment that by the EC-conditions, admiration of Garrison and revulsion at Shaw are warranted. ${ }^{16}$ What would warrant a viewer in feeling the same way about Garrison and Shaw after leaving the cinema? Merely imagining what is fictionally true - that Garrison is noble and self-sacrificing, or that Shaw is sleazy and dangerous - does not seem to be enough by itself to make admiration or revulsion a warranted response in the RWC. This is especially apparent given that, by all accounts, Stone's representation of the historical events is radically misleading. Shaw was most likely an upstanding, innocent citizen hounded literally to his early death by Garrison, whose obsessive suspicions and prosecutions were marked by a disregard for the truth that shocks even conspiracy theorists. ${ }^{17}$ Admiration of Garrison and revulsion at Shaw are thus unwarranted emotions in the RWC, regardless of how we construe the EC. Similarly, no matter how vividly I imagine Barack Obama delightedly drowning puppies, this imagining will not warrant real-world abhorrence of the US president.

Consider three different viewers of JFK, Larry, Moe, and Curly. Larry is fully aware of the history of Garrison and Shaw. Although he responds with admiration of Garrison and revulsion at Shaw while engaged with $J F K$, he does not believe Garrison to be noble or Shaw to be sleazy and dangerous. Were Larry nonetheless to admire Garrison and revile Shaw in the RWC, these responses would not be fitting; indeed they would strike us as irrational. ${ }^{18}$ Moe, on the other hand, having little background information about the JFK assassination, buys into Stone's propaganda. He believes that the film represents events accurately, so his admiration of Garrison and revulsion at Shaw are entirely fitting. But suppose that there is ample evidence that Stone's film is massively inaccurate about Garrison and Shaw, and this evidence is easily available to Moe; yet he ignores it because he is attracted to conspiracy theories. In this case Moe is unjustified in responding as he does. Curly, like Moe, takes $J F K$ to be accurate, but he does so because his friend, a respected historian, has told him (falsely) that JFK is a truthful record of events. Curly's real-world evaluations may be epistemically adequate even if they are in fact mistaken. So his admiration and revulsion are justified though incorrect. ${ }^{19}$ It seems as if Larry, Moe, and Curly are all warranted in admiring Garrison and reviling Shaw in the EC, but not in the RWC.

A natural conclusion is that there must be a substantial gap between emotional warrant when engaged with a fiction and emotional warrant in the RWC. But this conclusion, however natural, is mistaken. It is true that Larry, Moe, and Curly's responses in the RWC are unwarranted; however, so too are their responses in the EC. This is because of the sort of film JFK is.

\section{The Standard Scenario}

\footnotetext{
${ }^{16}$ I question this supposition in $\S 5$.

${ }^{17}$ See Friend 2003 as well as the citations in n.28.

${ }^{18}$ It is possible for someone to have conflicting beliefs, or to be mistaken about what she believes or about how she evaluates objects. Thus Larry, despite his explicitly held beliefs, might be influenced by $J F K$ to think better of Garrison or worse of Shaw. I take these to be genuine evaluations; there is no reason beliefs, for instance, must be conscious. But I ignore these complexities here.

${ }^{19}$ The contrasting examples are owed to Paloma Atencia-Linares.
} 
Audience response to JFK exemplifies what I call the standard scenario for carrying over emotions from the EC to the RWC. Leaving Larry's irrational response aside, why do Moe and Curly carry over their emotions toward Garrison and Shaw? The answer is simple: they take $J F K$ accurately to represent these real individuals. In the standard scenario, the audience responds with emotion E' in the $\mathrm{EC}$, and the film is taken to be accurate in portraying those aspects of a situation relevant to emotion E'. Moe and Curly's responses to JFK meet these conditions. They experience admiration of Garrison and revulsion at Shaw in the EC, and they believe - in one case with, in the other without, justification - that JFK represents Garrison and Shaw accurately. The cases of carryover mentioned in $\S 1$ also exemplify the standard scenario. Audiences take Hotel Rwanda accurately to convey the heroism of Paul Rusesabagina. Hearst was convinced, not without reason, that audiences would assume that Kane's reprehensible qualities were his own. The Hurt Locker has been lauded for capturing the emotional experience of real American soldiers serving in and returning from Iraq. These are all emotionally engaging films that, in one way or another, invite audiences to treat them as accurate. This is why they reliably elicit carryover.

None of this is to suggest that carryover occurs only in the standard scenario. Though emotional engagement is a prerequisite, emotions may carry over without an assumption of accuracy. For instance, if I am sufficiently worked up in response to a film portraying Obama drowning puppies, I might find myself feeling negatively about the president despite knowing that I have no reason to do so. Satires often exaggerate the flaws of public figures well beyond what anyone would take to be realistic, but may influence our attitudes nonetheless. ${ }^{20}$ If vengeance flicks depicting violence cartoonishly, or black comedies portraying murder as funny, influence our real-world responses (an empirical question), they do not do so via an assumption of accuracy. Despite the existence of these and no doubt many other cases, it is useful to get clear about the more straightforward case before introducing further complexities. Thus I restrict my focus to the standard scenario.

As previously noted, the defining feature of the standard scenario, given an emotionally engaged audience, ${ }^{21}$ is that the film is taken to be accurate with respect to features relevant to the emotion. "Taking a film to be accurate" does not necessarily mean possessing a conscious belief to that effect. Rather, audiences approach many films with an implicit, default expectation of accuracy (henceforth: EoA), at least with respect to certain features of the film. The EoA is widespread. There is empirical evidence that readers of fiction who do not have contradictory information are more likely to believe claims in a story to the extent that they are potentially applicable to the real world: for instance, general information about soldiering in Iraq as opposed to specific information about particular characters (see Prentice and Gerrig 1999 for a summary). Some experiments show that with particularly "transporting" texts - that is, texts that focus attention, prompt imagery, and engage us emotionally — readers are just as likely to believe what they read in texts labeled 'fiction' as in those labeled 'nonfiction,' even readers ordinarily prone to scrutinize information (Green and Brock 2000, 2002). Other experiments indicate that at least some readers are more likely to take certain facts for granted in fiction than in nonfiction (Prentice and Gerrig 1999). Although these studies focus on the cognitive influence of literary works, the point applies to features of film not translatable into propositions. For instance, audiences may take a film to be accurate with respect to the way a particular place looks, or an actor might be especially good at conveying how someone's face would change in a certain situation; and perceptual features can certainly influence our emotional responses. ${ }^{22}$ Thus the default approach to fiction is to assume that the fictional world is the same as the real world unless there are reasons to think otherwise. Where this EoA exists we are dealing with the standard scenario.

\footnotetext{
${ }^{20}$ This example was suggested by Paloma Atencia-Linares.

${ }^{21}$ I will take this as given in the rest of the paper and focus on the assumption of accuracy.

${ }^{22}$ As with emotional contagion (see n.5).
} 
A case in point is the nearly universal expectation that films will be psychologically realistic in portraying people's behaviors, motivations, expressions, and so forth. ${ }^{23}$ This is not an expectation on which audiences are likely to have reflected explicitly. It becomes explicit when it is defeated: that is, when a film is psychologically unrealistic. This may be due to a script that implies systematically irrational motivations on the part of characters, or perhaps simply the result of poor acting. Apart from certain kinds of avant-garde or surrealist cinema, ${ }^{24}$ a failure at accuracy with respect to typical human psychology is treated as a reason to criticize a film. Though few EoAs are as wide in scope as the presumption of psychological realism, which applies even to the most outlandish fantasies or sci-fi flicks, genre conventions frequently lead to expectations of other kinds of accuracy. Audiences of realistic films, for example, expect accuracy concerning physical laws; of historical dramas accuracy concerning well-known historical facts (consider the dismay at obvious anachronism); and so on. Knowledge of a particular filmmaker can lead to even more specific EoAs. Despite the many flaws of James Cameron's Titanic (1997), viewers knowledgeable about Cameron's methods will take the movie to provide the most accurate reproduction of the ship and the sinking ever filmed.

There are two lessons to draw from these observations. First, the audience's EoA directly affects the likelihood of emotional carryover. Suppose a viewer responds to the scenes of people falling from the upright stern of the Titanic into the still-churning engines below with intense feelings of horror, struck by the conviction that this would be a particularly terrible way to die. If he mistakenly thinks that Cameron dreamed this up merely for dramatic effect, he is unlikely to carry over these feelings to the RWC. In the standard scenario, it is typically only when a viewer thinks a film is accurate that carryover occurs.

Second, a film's being accurate in one way need not imply that it is accurate in another. A psychologically realistic fantasy film may (fictionally) break most of the physical laws of the known universe. A docudrama might be scrupulously exact in conveying details of the life of Henry VIII while making up various minor characters. The fact that the Henry VIII film is not truthful in all respects will not prevent an audience from carrying over their feelings about the Tudor king, just as an audience of Hotel Rwanda need not assume that Don Cheadle looks or acts exactly like Paul Rusesabagina in order to carry over their admiration. What matters for emotional carryover is accuracy with respect to those features relevant to a given emotion. Precisely which features of a film are relevant to which emotional responses is a difficult question; however, the difficulty is general. Apart from reflexive reactions to highly specified stimuli-for instance, the startle response to a sudden loud noise - emotions are highly and often unpredictably sensitive to a wide variety of factors (see Ekman et al. 1985). We are probably unaware of most of what influences our emotions, whether in the EC or the RWC. It remains the case that when we are dealing with the standard scenario, the EoA with respect to those features of a film that are (in fact, whether or not we are aware of it) relevant to an emotion increases the likelihood of carryover.

\section{Expectations of Accuracy}

Of course just because the standard scenario makes it likely that audiences will carry over their emotions does not mean that they are right to do so. It seems as if emotions that are fitting, justified, and correct in the EC need not be so in the RWC. This is the challenge presented by emotional carryover: how to bridge the gap between the two kinds of warrant. But this way of posing the challenge fails to take into account the profile of the standard scenario. Where $\mathrm{E}$ is an emotion in the RWC that carries over from an emotion E' in the EC, I claim that in the standard scenario, if E' is warranted, E is ipso facto warranted. Why? The key is the expectation of accuracy. In the standard

\footnotetext{
${ }^{23}$ Thanks to Tom Crowther for emphasizing the significance of this point.

${ }^{24}$ Such as David Lynch's Eraserhead (1977) or Tim Burton's Alice in Wonderland (2010). Thanks to Paloma Atencia-Linares for drawing these films to my attention.
} 
scenario, E' will not count as warranted unless the film meets the expectation; where it is met, E is warranted. Warrant in both contexts requires meeting an EoA. As a result, E' cannot be warranted unless $\mathrm{E}$ is. This is why the gap closes.

It is fairly obvious that where an appropriate EoA is not met, an emotion carried over into the RWC will not be warranted. Given that Désirée (Henry Koster, 1954) is a story of romance and intrigue only loosely based on the facts about the relationship between Napoleon Bonaparte and Désirée Clary, audiences are not warranted in forming attitudes toward the real historical figures on the basis of the movie. It is more controversial that when a film fails to meet an appropriate EoA, emotions in the EC are also unwarranted. One might think that accuracy has nothing to do with how we respond when we are emotionally engaged in a film; but this view is mistaken.

Consider again the widespread expectation that films will be psychologically realistic, this time with an example. In Mr. Holland's Opus (Stephen Herek, 1995) the title character, an ambitious musician played by Richard Dreyfus, takes a job teaching at a high school and eventually comes to recognize the importance of his neglected relationship with his son. Carl Plantinga provides a nice summary of the climactic scene of the film:

His penance comes in the form of an improbable and impromptu solo performance at a public concert, during which he sings John Lennon's "Beautiful Boy (Darling Boy)" to his deaf son in the audience. But why should the spectator so easily accept this sudden change of heart, given that, aside from this impromptu performance, we have seen little evidence of Holland's improved parenting? And why should the audience at the concert be interested, given that even those who know Holland personally are unlikely to be aware of the miserable relationship between him and his son? ... The intended empathy here is unearned and improbable, and therefore sentimental. (Plantinga 1999, 251-52).

As Plantinga points out, this scene is wholly implausible with respect to character development and motivation; it is sentimental drivel. Yet the filmmakers employ multiple techniques, including closeups of affectively charged facial expressions along with uplifting music, designed to elicit emotion from viewers. A sufficiently critical viewer may successfully resist the emotional manipulation and feel nothing but contempt and a desire to leave the theater. Unfortunately I can affirm from personal experience that Mr. Holland's Opus can provoke even the most cynical viewer to experience tearful sympathy. Yet the fact that this response is practically irresistible does not mean that it is warranted; as Plantinga says, this is an unearned, sentimental response. A competent viewer will recognize that she is being manipulated to experience emotions that are unwarranted in the EC. And the reason they are unwarranted in that context is precisely that they are psychologically unrealistic: they do not accurately represent the genuine psychological motivations of human beings. Conventions for most fiction determine that emotions in the EC can be warranted only if they involve evaluations that are correct with respect to psychological attributes in reality.

As this example illustrates, it should be uncontroversial that warrant for emotions in the EC requires meeting at least one kind of EoA, namely with respect to psychological motivation. The controversy is over whether more specific EoAs, such as those concerning historical facts, must be met for emotions experienced while engaged with a film to be warranted. Again, it is obvious that if the EoAs are met, warrant in the RWC is secured. Since Hotel Rwanda is accurate with respect to the main actions taken by Paul Rusesabagina (who advised the filmmakers) in saving Tutsis at his hotel during the genocide, carrying over one's admiration to the real person is warranted. The point of contention is the claim that if an emotion E carried over into the RWC is (or would be) unwarranted, then so too is emotion E' in the EC. In other words, the contentious claim is that E' cannot be warranted unless $\mathrm{E}$ is 
(or would be). ${ }^{25}$ In the rest of this section I examine two films that invite carryover of emotions toward real groups or individuals, The Hurt Locker and JFK. I argue that in each case emotion E' in the EC is unwarranted for the same reason as emotion E in the RWC is unwarranted: the failure to meet the EoA.

\section{Case 1: JFK}

$J F K$ depicts real historical individuals and events. ${ }^{26}$ Many audiences assume that $J F K$ is meant to be accurate with respect to these individuals and events, not just broadly, but in the details as well. The standard interpretation is that the film is intended to persuade audiences of Jim Garrison's claim that a military-industrial-governmental conspiracy, involving among others Vice-President Johnson, was behind the Kennedy assassination. This interpretation can be explained in part by Stone's skillful integration of documentary and amateur footage with scenes involving actors and sets. But it receives support from Stone's own statements and actions. For example, Stone has been quite explicit that JFK was designed to get across his view that factions in the military-intelligence community, and not Lee Harvey Oswald acting alone, were responsible for Kennedy's assassination. ${ }^{27}$ Stone has not only vehemently defended the factual accuracy of the film, he used it as a platform in campaigning to have government files on the assassination released to the extent of meeting with Congressional leaders. In 1992 Congress passed the JFK Assassination Records Collection Act, making available most of those files.

As previously noted, most people who know anything about the real events view JFK as riddled with inaccuracies, and not just about Garrison and Shaw. ${ }^{28}$ The movie falsely suggests, for example, that Lyndon Johnson reversed Kennedy's plans to deescalate the Vietnam War upon taking office. This is in line with the assumption that propels the entire plot, namely that the motive for assassination was the desire of the military-industrial complex to overturn this and other nonconfrontational Kennedy policies. As a result, JFK has been subject to severe criticism. In 1992 Jack Valenti, then president of the Motion Picture Association of America and previously a top aide to Lyndon Johnson, condemned the movie in a statement.

"In scene after scene Mr. Stone plasters together the half true and the totally false and from that he manufactures the plausible," Mr. Valenti said in his statement. "No wonder that many young people, gripped by the movie, leave the theater convinced they have been witness to the truth. ... 'Both 'J. F. K.' and 'Triumph of the Will' are equally a propaganda masterpiece and equally a hoax." 29

Significantly, Valenti does not take the fact that JFK is fiction and Triumph of the Will nonfiction to have any bearing on the former's persuasive effect or its merit. He assumes that $J F K$ is designed to persuade. Even those who praise $J F K$ typically take it to be aiming for accuracy. Roger Ebert, who

\footnotetext{
${ }^{25}$ The parenthetical qualification indicates that the entailment works even if carryover does not occur in a particular case, i.e., the viewer does not come to feel E. E' cannot be warranted unless E would be warranted. I omit the qualification in what follows but it should be understood.

${ }^{26}$ For defense of this claim, see Friend 2003.

${ }^{27}$ See, for example, Stone's statements in Carnes 1996 and his comment on James Douglas's book JFK and the Unspeakable, posted July 23, 2009, on The Huffington Post.

${ }^{28}$ George Lardner was the first writer to criticize $J F K$ for extensive distortion even before the film was completed, in his Washington Post article "On the Set: Dallas in Wonderland," on May 19, 1991. See also Epstein 1993 for further discussion of the inaccuracies.

${ }^{29}$ As Bernard Weinraub reported in a New York Times article on April, 2 1992, titled "Valenti Calls 'J.F.K.' 'Hoax' and 'Smear.'”
} 
later called JFK the best film of 1991, spends a good part of his review of the film by arguing that Stone is right in insisting that the assassination must have been the work of a conspiracy. ${ }^{30}$

There can be no doubt that many audiences of $J F K$ expect accuracy with respect to known facts about the historical people and events it portrays. Let us assume that the EoA is appropriate, putting off questions about this assumption to the next section. At the same time, there can be no doubt that $J F K$ seriously distorts the facts. This distortion, I argue, undermines warrant for emotions not only in the RWC, but also in the EC.

Given what Curly has been told about the accuracy of $J F K$, we can assume that he not only imagines Garrison as nobly pursuing the truth and Shaw as contemptibly engaging in conspiracy; he also believes that this reflects what actually happened. Indeed the film invites audiences to believe just this, insofar as the EoA concerning the historical facts is appropriate. If we expect a film to be accurate in a particular respect given what we know about the genre and/or filmmakers, then we assume that at least in that respect the fictional world is just like the real world. More specifically, we assume that the fictional world is the way it is because that is the way the real world is. ${ }^{31} \mathrm{We}$ take the filmmakers to be guided by a norm of accuracy. This norm has direct consequences for appropriate emotional engagement. It implies that if Curly is warranted in admiring Garrison in the EC, then he is ipso facto warranted in admiring Garrison in the RWC. More strongly, the implication is that he should admire Garrison in the EC because he should admire him in the RWC. It follows that if the admiration is unwarranted in the RWC - which, given what we know about Garrison, it is - it is also unwarranted in the EC. And it is unwarranted in the two contexts for the same reason: the failure to meet an appropriate EoA.

\section{Case 2: The Hurt Locker}

By contrast with JFK, I assume that the main characters and events of The Hurt Locker (henceforth: $T H L$ ) are invented. ${ }^{32}$ Nonetheless many audiences take these characters and events to represent the experiences of real people, specifically American military bomb squads in Iraq. In the film we follow a three-man US Army Explosive Ordnance Disposal (EOD) team during the last thirtyeight days of their rotation in Iraq in 2004. The new leader of the unit, Sergeant Will James (Jeremy Renner), is responsible for defusing the bombs. He is accompanied by veteran Sergeant J.T. Sanborn (Anthony Mackie) and a raw recruit, Specialist Owen Eldridge (Brian Geraghty); they become increasingly afraid for their lives with James, who seems reckless to the point of a death wish. The film develops a level of tension and pace of action that rarely lets go over two hours. THL is, by all accounts, a great action flick. But it is typically taken to be more. With the intensely close focus on the three-man team, the script by Mark Boal suggests no overarching political statements about the Iraq war. Nonetheless everyone, admirers and detractors alike, characterize this as a movie about Iraq and specifically about what it's like to be in an EOD unit in $2004 .{ }^{33}$ Boal's script is based on his experience embedded with an Army bomb squad in Iraq during that period. Bigelow shot the film in Jordan close to the border with Iraq for the sake of authenticity. When the movie came out in the US, the producers

\footnotetext{
${ }^{30}$ In the Chicago Sun-Times, December 20, 1991.

${ }^{31}$ Some authors take this constraint as a defining feature of nonfiction as opposed to fiction, for example David Davies (2001), Gregory Currie (1990), and Peter Lamarque and Stein Haugom Olsen (1994). I criticize this view in Friend 2008.

32 This assumption has been questioned by an Iraq War veteran, Jeffrey Sarver, who filed a lawsuit in March 2010 accusing the filmmakers of negative misrepresentation in basing the main character on him, an accusation they deny. If Sarver is right, $T H L$ is like $J F K$ in this respect. I assume otherwise to focus on a different kind of case.

${ }^{33}$ In one of many examples, New York Times film critic A. O. Scott called it "the best nondocumentary American feature made yet about the war in Iraq" in his review of the film on June 26, 2009.
} 
set up special showings for Iraq veterans followed by panel discussions with the filmmakers. By and large audiences seem to expect the film to be accurate in certain respects: not in every way, but at least in terms of the plausible experience of soldiers in Iraq, especially those whose job it is to defuse bombs. As Paul Rieckhoff, executive director of Iraq and Afghanistan Veterans of America, puts it: "Most Americans walking into this film, if they follow the marketing and the critical acclaim, are going to think that this is how Iraq is" (Hornaday and Rieckhoff 2010). Whether or not the expectations are appropriate is a different question, to which I return below.

A number of critics, particularly Iraq veterans such as Rieckhoff, have argued that the film does not meet these common expectations. The criticisms range from points about detail, for instance the use of incorrect uniforms, to more substantive inaccuracies. ${ }^{34}$ Michael Kamber, a photojournalist who has documented the work of explosive ordnance teams, describes some of these: ${ }^{35}$

If there is one rule with the military, it is that there is strength in numbers. No one soldier, no one vehicle, goes out alone. Ever. Four vehicles and a 20 -man squad is the minimum that I have worked with in Iraq. A lone Humvee would not be allowed to clear the gate at any base in Iraq.

Yet, in scene after scene, the bomb disposal team, led by Staff Sgt. William James, appears to be fighting the war alone. They drive the streets of Baghdad, a three-man team in a lonely Humvee, with no back up. They single-handedly clear buildings, drive desert roads alone with no air cover and confront a truckload of potential enemy fighters - who turn out to be bizarre and incompetent British mercenaries. When the British are killed, the American explosive technicians turn out to be expert snipers and spotters as well.

For the present, let us assume that the critics are right: it is appropriate to expect $T H L$ to be accurate concerning the way in which EOD units operate in Iraq, and the film fails to meet this expectation. The question is what effect this failure would have on warrant for emotions in the EC.

THL clearly prescribes, among other evaluations, that viewers imagine members of the fictional EOD unit to be confronting enemy fighters and clearing out buildings alone. If the EoA is appropriate, the film also invites viewers to think of members of real bomb disposal squads as confronting enemy fighters and clearing out buildings alone. The norm of accuracy implies that the fictional EOD unit engages in these actions precisely because real EOD units do so. Suppose that Aaron, like many viewers unfamiliar with the controversy, assumes that $T H L$ is a largely accurate reflection of what life was like for an EOD team in Iraq around 2004. He is struck by the incredible courage and skill of the men strained beyond ordinary human limits, isolated from any support. He experiences admiration bordering on awe, combined with fear at the dangers they face. Assume that Aaron's emotions are specifically responsive to the (fictional) fact that the EOD team operates alone. ${ }^{36}$ The film prescribes admiration and fear for the fictional bomb squad for this reason. Since it is supposed to be accurate, it also prescribes admiration and fear for real bomb squads for the same reason. We know, however, that the film is inaccurate in this respect. Though there are many good reasons to admire and fear for soldiers in Iraq, confronting enemies in total isolation is not one of them. If Aaron were to carry over his admiration and fear, directing them toward real soldiers in real EOD units, his emotions would be

\footnotetext{
${ }^{34}$ In addition to Rieckhoff 2010, see also Kate Hoit's contribution to The Huffington Post, "The Hurt Locker Doesn't Get this Vet's Vote," posted on February 4, 2010.

${ }^{35}$ In a contribution to the New York Times Lens Blog posted March 1, 2010, titled "How Not to Depict a War."

${ }^{36}$ This is a simplifying assumption. As noted in $\$ 4$, it can be extremely difficult to tell which features are relevant to an emotion. For example it might be that Aaron's emotions would not change, or not by much, if the EOD operations were supported by other units in the film (as Paloma Atencia-Linares has pointed out to me). I assume otherwise for the sake of argument.
} 
unwarranted in the RWC. ${ }^{37}$ But insofar as an EoA is appropriate, $T H L$ does not simply prescribe admiration and fear in the EC as well as the RWC; it implies that the former emotions are warranted because the latter are. Thus if Aaron's emotions in the RWC are unwarranted, so too are his emotions in the EC. And both are unwarranted for the same reason: the failure of accuracy.

It is important to note that these inaccuracies do not undermine warrant for every possible emotion one might have in response to THL. Even critics acknowledge that the film does a good job portraying the difficulties faced by soldiers attempting to re-assimilate to civilian life upon returning home. Furthermore, by all accounts the film captures much of the visceral intensity and tension experienced by bomb squads and other soldiers. If Aaron sympathizes with the struggle of returning soldiers to re-assimilate, or fears for real soldiers facing danger in general, these emotions may well be warranted. If they are, it will be because the film meets the relevant EoAs concerning such experiences of soldiers in Iraq. Where it fails to meet EoAs, the emotions are not warranted.

\section{The Inappropriate Expectations Objection}

There is an obvious worry about this argument. Isn't it just implausible that emotion E' in the EC is warranted only if emotion E in the RWC is warranted? Even if it is the case that real EOD teams do not heroically confront the enemy alone, Sergeant James's fictional unit in THL does. Don't the fictional soldiers deserve admiration for these actions regardless of whether or not real soldiers do? Similarly, despite Stone's intention to propagandize, JFK is a fiction film. Shouldn't we construe audience responses while engaged with a fiction to be distinct from their responses in the RWC? If so, the fact that the real Garrison did not deserve admiration is neither here nor there with respect to appropriate responses to the film. All that matters is that Garrison-as-portrayed-in-the-film warrants the admiration of audiences.

There are two distinct objections that can motivate this worry, and it is important to keep them apart. According to the first, the reason that warrant for emotions in the EC is independent of warrant in the RWC is that THL and JFK do not invite the expectations of accuracy I have described. Audiences who expect THL to be accurate about the operations of EOD units in Iraq, or JFK to be accurate about the actions of real historical individuals, have made a mistake. These expectations of accuracy are not appropriate. The fictional worlds of the films are just different from the real world and invite different responses. Call this the inappropriate expectations objection. I address it in this section. The second objection is that even if the films invite those EoAs, their failure to meet them undermines warrant only in the RWC, and not in the EC. The conditions of warrant for the two contexts are independent. Call this the independent conditions objection. I address it in $\S 7$.

The first point to make about the inappropriate expectations objection is that even if it is right it is technically irrelevant to my argument. I have argued that where there is an appropriate EoA, emotion E' in the EC is warranted only if emotion E carried over into the RWC is warranted. I agree that if the EoA is inappropriate, carryover is unwarranted independently of warrant in the EC. It is only on the assumption that an EoA is appropriate that a failure of warrant in one context implies a failure of warrant in the other. Even granting this, however, if it were totally implausible that EoAs are appropriate for THL and JFK that would undermine the force of the argument, which after all is by cases. Worse, if the reasons to doubt the appropriateness for those films were to generalize, that would significantly reduce the scope of the argument. Therefore it is worth addressing the objection directly.

\footnotetext{
${ }^{37}$ Notice that Aaron's being unaware of the film's inaccuracies does not change this result, nor does the fact that most ordinary viewers cannot be expected to know much about the operations of bomb squads in Iraq. The RWconditions include not merely justification, but correctness. Thus even if Aaron is in no way epistemically irresponsible, these emotions are not fully warranted. Thanks to Paloma Atencia-Linares for pressing me to clarify this issue.
} 
It is not easy to argue that the EoA is inappropriate for JFK given Stone's explicit defense of the film's factual accuracy. The only avenue seems to be to insist that because it is classified as fiction, no EoA, or no EoA concerning historical facts, is appropriate. Yet that is implausible. Realist historical fictions, including those that are intended to be much less accurate than $J F K$, invite an EoA with respect at least well-known facts. $J F K$ is not counterfactual historical fiction, aiming to imagine the way the world might have been had such facts been different; contrast the television movie Fatherland (Christopher Menaul, 1994), which offers a picture of 1960s Germany if Hitler had won. It is not a work of satire or farce that plays with historical facts for comic effect; contrast Mel Brooks's The History of the World: Part I (1981), which uses historical figures and events as backdrop for a series of jokes. Indeed $J F K$ is more than an imaginative foray into realist historical fiction, since the avowed aim of the filmmakers is to persuade people to change their beliefs. $J F K$ is closer to a dramatic reenactment of historical events, if a wildly misleading one, than to a standard fiction film. And the fact that the film is misleading is due not to creative license, but to Stone's false beliefs. So although we need not insist on accuracy with respect to every detail, it is reasonable to expect accuracy with respect to the main individuals and events depicted.

$J F K$ is, however, unusual. Most fiction films that generate an EoA could not be described as dramatic reenactments or propaganda. This includes $T H L$. Not only are the characters and events that form the focus of Bigelow's film fictional, what we know about the filmmakers' intentions and relevant genre conventions lends support to the objection. The film's military advisor, James Clifford, has described it as no more than "entertainment based on real situations" 38 while screenwriter Boal said they made "creative choices for dramatic effect." 39 In other words, the filmmakers intentionally changed various aspects of the real situation to make for a more compelling film, much as Shakespeare intentionally compressed and shifted chronology in the history plays. Arguably the inaccuracies allow the filmmakers to convey a larger "emotional truth" about the experience of soldiers in Iraq, in particular how it feels to face those life-threatening situations everyday. ${ }^{40}$ Moreover, this interpretation accords with the history of war movies, particularly movies that use war as a backdrop for action. ${ }^{41}$ Many such films, from The Dirty Dozen (Robert Aldrich, 1967) to Saving Private Ryan (Steven Spielberg, 1998), depict unrealistic feats by individuals or isolated units. Perhaps critics who compare THL to other films about Iraq (whether fiction or non-fiction) have placed it in the wrong category. If so, audiences who expect $T H L$ to be accurate about the real conditions under which EODs operate are asking for too much. On this view, the film was never intended to inform audiences about these conditions, and thus should not be criticized for failing to do so.

I take these considerations to show that the inappropriate expectations objection is plausible for THL; but I do not think they are definitive. Again, my argument does not require proving that an EoA concerning the operations of EOD units is appropriate for this film. It does require, however, showing that it could be appropriate, i.e., that it is not implausible to think that it is. For if the considerations adduced in the previous paragraph were sufficient to show that an EoA is inappropriate, the result would generalize to nearly any film in which the filmmakers distort the truth for dramatic effect. It would turn out that EoAs are appropriate only if the film is accurate or any inaccuracies are unintentional (based on false beliefs, as with Stone). That is much too extreme a conclusion.

Consider Michael Moore's first documentary film, Roger and Me (1989). In the film Moore depicts, often in a wryly humorous way, the aftermath of the devastation wrought on his hometown of

\footnotetext{
${ }^{38}$ In a contribution to The Huffington Post, "The Hurt Locker: A Vet's View," posted February 8, 2010.

${ }^{39}$ Quoted in a posting on the LA Times The Envelope Blog, "“The Hurt Locker' Sets off Conflict," by Julian E. Barnes, Ned Parker, and John Horn (February 25, 2010).

${ }^{40}$ This point is made by James Clifford (see n.38) and echoed by Ray Odierno (2010). The term "emotional truth" is Ann Hornaday's in Hornaday and Rieckhoff 2010.

${ }^{41}$ Thanks to Chad Grine for drawing my attention to such films.
} 
Flint, Michigan, by the decision of General Motors to close several auto plants there. During the timeframe of the film, 1986-1989, one plant after another closes while Moore attempts repeatedly and unsuccessfully to gain an interview with Roger Smith, the CEO of GM, ostensibly to persuade him to come to Flint to see what is happening. Smith's brush-offs support the film's contention that Smith is a selfish corporate head who does not care about the lives he has ruined. When I saw this film, I (like many other people) took for granted that it adhered to a norm of accuracy for documentaries. I responded accordingly, condemning Smith's coldness, sympathizing with the various people who had lost their livelihoods, and so on. Many of these responses were warranted, but at least some were not. It turns out that much like Shakespeare, Moore compressed and altered the chronology of events, not least the plant closures which actually took place over a dozen years. To take a more specific example, the film shows singer Pat Boone, who had been a Chevrolet spokesman in the 1950's and 60's, returning to Flint ostensibly to cheer up the unemployed after the plant closures. While there Boone calls Roger Smith a "can-do kinda guy," a comment for which he was vilified by audiences of the film. Similarly, we see Ronald Reagan visiting the city in what is ostensibly a response to the crisis. He has pizza with a group of unemployed autoworkers and tells them to move to Texas. ${ }^{42}$ When I saw the film, I was appalled at the insensitivity displayed by both Boone and Reagan; there is no doubt it affected my feelings toward them. But I later discovered that my feelings were unwarranted. Both visits to Flint took place before the plant closures. In fact Reagan's pizza discussion was a presidential campaign stop in 1980.

Now, it must be said that Moore does not include many dates in the film. So there is a sense in which the film is not explicitly committed to an identification of the chronology of scenes with the chronology of real events. Surely, however, a competent viewer will make this inference, and in particular the inference that the Reagan and Boone visits were responses to the plant closures that form the subject of the documentary (why else would they be included?). If this is right, then Moore intentionally distorted the truth for dramatic, or in this case sarcastic, effect. I take it that his doing so in no way undermines the appropriateness for Roger \& Me of an EoA concerning the chronology of real events. The expectation is appropriate, and Moore fails to meet it.

It might seem that because Roger \& Me is a documentary, this conclusion has no bearing on the plausibility of an EoA for $T H L$ or other fiction films. One could object that nonfiction works are supposed to be accurate; intentional inaccuracies constitute deceptions and are therefore flaws. This is (the objection continues) in stark contrast to works of fiction, where accuracy is not the goal; intentional distortions of the truth are therefore acceptable for fiction. I have argued elsewhere (Friend 2006,2008 ) that these generalizations about fiction and nonfiction are mistaken, so here I will be brief. It is simply not true that all works of nonfiction are supposed to be accurate in every respect; and it is equally untrue that no works of fiction are supposed to be accurate in some respect. Classical Greek and Roman historians made up speeches and battle descriptions, in part to preserve the stylistic continuity of their works. Many authors of fiction engage in painstaking research to get certain facts right. The point applies equally to film. I have already mentioned that realist historical fiction films are supposed to be accurate with respect to at least the well-known facts. On the other side of the coin, dramatic reconstructions in documentaries are not expected to be accurate about the exact appearances or behaviors of the real individuals represented. ${ }^{43}$

\footnotetext{
${ }^{42}$ This example is discussed by Pauline Kael in her review of Roger \& Me in The New Yorker on January 8, 1990.

${ }^{43}$ For another example: although I believe that an EoA concerning chronology was appropriate for Roger \& Me in 1989, I would say it is inappropriate today, and for most other Michael Moore documentaries. By now Moore's methods are well-established. Audiences who assume the chronology implied by his films is supposed to be accurate are just mistaken.
} 
Still, the fiction label does suggest a reduced concern with accuracy. Unless fiction films purport to tell the historical truth, as JFK does, even those "based on a true story" are not criticized for making up characters or events (so long as these are in some way based on the true story). But even the most outlandish fiction films are constrained by plausibility in representing reality. The fact that Independence Day (Roland Emmerich, 1996) is a science fiction fantasy does not prevent us from criticizing the climactic scene, in which the heroes use a Mac to infect the alien mother ship with a virus. How likely is it, we find ourselves asking, that the IT system onboard the mother ship is compatible with an Apple computer? The expectations of plausibility are greater to the extent that the film is perceived as realistic. Where we are talking about a film in which the characters and events portrayed fall into identifiable, historical groups, we typically expect them to be at least plausible members of those groups. If the fictional soldiers in $T H L$ are not credible as an example of an EOD unit in Iraq due to the inaccuracies in the film, this is grounds for criticism, even if the incredibility is the result of intentional distortions on the part of the filmmakers. I conclude that it remains plausible that an EoA is appropriate for THL (and other fiction films), even if it does not have the persuasive ambitions of a movie like $J F K$.

\section{The Independent Conditions Objection}

I turn now to the second objection designed to undermine the claim that emotion E' in the EC is warranted only if emotion E in the RWC is warranted. According to the independent conditions objection, even if the EoAs are appropriate for $J F K$ and $T H L$ this is not sufficient to undermine warrant in the EC. Warrant in the EC is determined by the EC-conditions ( $\left.F^{\prime}\right),\left(J^{\prime}\right)$, and ( $\left.C^{\prime}\right)$, and emotional responses to the two films appear to meet those conditions. For instance, Aaron's admiration and fear assume that Sgt. James and his unit confront enemies and clear buildings alone. The film shows them doing so. A competent viewer deploying appropriate principles of generation will have no reason to doubt that what she sees is fictionally the case, and nothing in the rest of the film undermines this conclusion. Because the plot of $J F K$ largely follows an investigation after the fact, it relies more on characters' testimony about various events than on showing them. Nonetheless, it is clear to the competent viewer that Garrison is fighting for the truth, that Shaw is involved in the assassination, that the military-intelligence community is behind it, and so on. These are the evaluations involved in Larry, Moe, and Curly's admiration of Garrison and revulsion at Shaw in the EC. Since in both cases the relevant evaluations are fictionally adequate and represent the fictional properties of the objects of emotion, the emotions meet $\left(\mathrm{F}^{\prime}\right),\left(\mathrm{J}^{\prime}\right)$, and $\left(\mathrm{C}^{\prime}\right)$. The fact that emotions toward real soldiers or particular historical figures carried over from the film might fail to meet RW-conditions (F), (J), and (C) is a separate matter. The objector concludes that the gap between the EC and the RWC remains. Emotion E' can be warranted in the former when $\mathrm{E}$ is unwarranted in the latter.

There are, I think, two possible replies to this objection. The first is that conditions (F'), (J'), and $\left(C^{\prime}\right)$ do not exhaust the criteria of warrant for the EC. Even if Aaron's admiration of and sympathy for Sgt. James's unit meet these conditions, they fail to meet other criteria. The second reply is that despite appearances, such emotional responses do not meet the EC-conditions. I take each reply in turn.

Livingston and Mele (1997), following Currie (1990), claim that moral, pragmatic, and artistic criteria are relevant to determining "artistically justified" responses to a work, over and above questions of justification or correctness. On their view, if an anti-Semitic story portrays Jewish characters as murdering children, the congruent emotion is abhorrence; but this emotion may still be deemed inappropriate insofar as it requires entering into an immoral point of view. Pragmatic factors include genre conventions and the artist's intentions. Knowledge that a fiction-maker intends to represent a particular real individual might make a congruent response unwarranted if the facts are problematically distorted. Similarly, Currie $(1990,213)$ claims that in cases such as black comedy, the appropriate response (e.g., amusement) can be highly incongruent with the depicted events (e.g., 
suffering). ${ }^{44}$ Finally, artistic skill can be relevant. The congruent response to a scene of someone dying of a terminal illness might be sadness, but if the film is mere sentimental rubbish this response will not be artistically justified. Livingston and Mele $(1997,174)$ conclude that an emotional response is artistically justified so long as either (i) it is congruent and the moral, pragmatic, and artistic criteria are fulfilled; or (ii) it is incongruent because the work is flawed morally or artistically. I will set questions of ethical merit aside here for I am not convinced they are matters of warrant. Pragmatic and artistic considerations, by contrast, can potentially make a difference to the responses warranted by a work.

An argument could be made that $T H L$ and $J F K$ are just too artistically flawed for emotional responses in the EC to be justified. This is clearly the view of many critics, such as veterans who find it impossible to become engaged with $T H L$ due to the inaccuracies. One might argue that the filmmakers in this case are just lazy. ${ }^{45}$ They do not bother to get the details right even about the uniforms. They employ standard action movie devices and implausibly isolated characters to elicit strong emotional reactions, instead of taking the time to develop a story about the realities faced by EOD soldiers in Iraq-a story the screenwriter knows full well. Stone does not ignore what he knows for the sake of effect; he apparently believes what he portrays in JFK. Still the falsehoods throughout the film could constitute artistic flaws in $J F K$ if we think that cognitive value is relevant to aesthetic value. No matter how impressive Stone's cinematography and editing, if certain epistemic conditions are not met JFK is flawed artistically. The same would apply to $T H L$. If we agree that artistic flaws affect warrant for emotional responses, we have a reason to take accuracy to be a criterion of warrant in the EC.

Even if both films are artistically flawed in these ways, however, it is not clear that this by itself undermines emotional warrant. Not every flaw in a film makes it inappropriate to respond emotionally. ${ }^{46}$ The fact that there are tire tracks visible in the sand near the amphitheater in a scene of Gladiator (Ridley Scott, 2000) does not mean all emotional engagement with the film is unwarranted. Even some degree of sentimentality is consistent with merited emotional responses. Furthermore, I do not think that inaccuracy is an artistic flaw per se (in either fiction or nonfiction). Indeed cognitivists do not typically defend the relevance of factual accuracy to aesthetic value, focusing instead on such cognitive values as psychological or moral insight. ${ }^{47}$ If these films are artistically flawed, it is not because they fail to meet some general artistic requirement of accuracy, but because they fail to meet specific EoAs determined by the genre or the methods of the filmmakers. It is plausible that such pragmatic factors establish conditions of success for a film. A comedy that fails to be funny is a bad comedy. A romantic film that is not romantic is a bad exemplar of its genre. Similarly, if a film elicits an appropriate EoA, then its failing to meet it means the film has failed to achieve one of its aims and is therefore flawed. The present objection allows that $T H L$ is meant to be accurate with respect to the operations of EOD units in Iraq but is not. This particular kind of flaw does plausibly undermine warrant for emotions, if those emotions are sensitive to features of the film that are supposed to be accurate. As I have argued, where there is an appropriate EoA, a film that invites emotion E' in the EC implies that emotion E in the RWC is warranted; where the latter is unwarranted, so too is the former. Therefore even if emotional responses to THL and JFK in the EC meet the conditions ( $\mathrm{F}^{\prime}$ ), ( $\left.\mathrm{J}^{\prime}\right)$, and $\left(C^{\prime}\right)$, they are unwarranted insofar as they are responsive to features of the films that are inaccurate and thus artistically flawed.

The second reply is that emotional responses to the films fail to meet the EC-conditions themselves, regardless of whether they fail to meet any further criteria. For example, Aaron's responses to $T H L$ arguably fail to meet ( $\left.\mathrm{J}^{\prime}\right)$. An EoA for a certain domain implies, at the very least, the

\footnotetext{
${ }^{44}$ Livingston and Mele (1997, 166-67) reject this part of Currie's account.

${ }^{45}$ This point is made explicitly by Kate Hoit (see n.34).

${ }^{46}$ Livingston and Mele $(1997,163)$ make a similar point.

${ }^{47}$ Friend 2006 is an exception
} 
principle of generation that fictional events must be consistent with real possibilities in the domain. Assuming that an EoA concerning the operations of EOD teams in Iraq is appropriate, this means that a relevant principle of generation is that fictional events must be consistent with real operating procedures for American bomb disposal squads in Iraq. If Sgt. James's unit acts alone, it functions in a way directly contrary to what is known about how EOD teams operate. The viewer who is aware of this has two choices. She can set aside her expectation that the film be accurate and respond in the ways it invites her to do, ignoring pesky questions about how it is possible for an EOD unit to display expert sniping ability and so forth. ${ }^{48}$ I suspect that this is the standard maneuver in cases of this kind, the way that we cope with bothersome inaccuracies. But even if this is the only way our viewer can enjoy $T H L$, her emotions in the EC remain unwarranted according to ( $\mathrm{J}$ '), since she has ignored at least one central principle of generation. Alternatively, if the viewer is unable to put aside her expectation of accuracy, she can reject what she sees onscreen as reliably indicating the way the fictional world is. After all, she reasons, the fictional world of THL is supposed to be, in central respects, the real world. The film might present Sgt. James's team as acting alone, but (the frustrated viewer exclaims) that just cannot happen. The application of appropriate principles of generation leads to a contradiction. On the one hand we are supposed to accept what we see onscreen as what happens; on the other we are supposed to think that what happens is what could plausibly occur in the real world. Even if we allow the former principle of generation to trump the latter, so that our emotional responses meet (C'), the conflict in principles undermines the possibility of meeting ( $\left.\mathrm{J}^{\prime}\right)$.

With $J F K$ the situation is slightly different. Given the EoA concerning the historical persons and events portrayed, and particularly the persuasive purpose of the film, there seems to be no distinction between the emotions audiences are invited to feel in the $\mathrm{EC}$ and the emotions they are invited feel in the RWC. ${ }^{49}$ The film prescribes admiration of the real Garrison and revulsion at the real Shaw, not in addition to or as a consequence of admiring and reviling fictional characters, but directly. Our engaged evaluations of the real individuals and events are supposed to be just the same as our realworld evaluations. If that is so, the emotions are warranted in the one context if and only if they are warranted in the other. As a result, the EC-conditions and the RW-conditions converge. I take it that this is the way we would ordinarily treat a dramatic reenactment in a documentary that aims to generate emotional responses toward real individuals. It is only insofar as the reenactment is accurate in emotion-relevant respects that the prescribed emotions, directed at the real individuals portrayed, are warranted. If we want to reject this analysis of $J F K$, insisting that there is a distinction between the conditions of warrant for emotions in the two contexts, we should say the same for documentaries, and not just with respect to dramatic reenactments. As the case of Roger \& Me shows, the emotions we are invited to feel while engaging with a documentary can depart substantially from the emotions we are warranted in feeling toward the real individuals and events portrayed. ${ }^{50}$

Either the first or second reply is, in my view, sufficient to meet the independent conditions objection. The second reply has the advantage of showing that the emotions in the EC are unwarranted even if we do not accept additional criteria of warrant over and above fittingness, justification, and correctness. But since the pragmatic/artistic criteria are plausible, the first reply will do just as well. Thus we have good reason to think that where an EoA is appropriate, failure to meet the expectation undermines warrant for emotions not only in the RWC, but also in the EC. The conditions of warrant are not independent.

\footnotetext{
${ }^{48}$ She might even call these "silly questions" in Walton's sense (1990, 174-183).

${ }^{49}$ Those who disagree may take the argument concerning THL to apply equally to JFK.

${ }^{50}$ The same point can be made with documentaries that involve neither dramatic reconstructions nor distortions of the sort Moore engages in. Documentary filmmakers edit and frame their footage to achieve various effects, thereby provoking emotional responses that can differ from those warranted by the real events. I discuss some cases of this phenomenon in Friend 2007.
} 


\section{Conclusion}

The challenge of explaining warrant for carryover is to bridge the apparent gap between the conditions of warrant for emotions in the EC and the conditions of warrant for emotions in the RWC. Intuitively, the fact that fear for fictional characters while engaged with a film is appropriate does not mean that fear for anyone in the real world is appropriate. What would warrant carrying over the fear from the one context to the other? I have claimed that when we are dealing with the standard scenario, carryover occurs as a result of an EoA concerning emotion-relevant features of the film. Given an appropriate EoA, if emotions in the EC are warranted, emotions in the RWC that result from carryover are ipso facto also warranted. It is not possible for emotions to be warranted in the EC if the carriedover emotions are not warranted in the RWC. This is why carryover is warranted for certain emotional responses to The Hurt Locker but not others: it is only insofar as fear for real soldiers is made appropriate by the film that fear for the fictional soldiers portrayed can be warranted. The film must meet the EoA for emotions in either context to be warranted. Again, the gap closes.

This conclusion has limited scope. As noted above, carryover is not the only mechanism by which films and other works of fiction influence our emotions. Films might put audiences in moods that make particular emotions more likely outside the cinema, or simply offer information that leads to emotions concerning real individuals or events. Furthermore, the standard scenario is not the only situation in which carryover occurs. For example, good satire may use unrealistic fictional characters and situations to provoke feelings toward real public figures; think of Charlie Chaplin's Hitler character Adenoid Hynkel in The Great Dictator (1940). If carryover is warranted in these cases, it is not because of the kind of EoA generated by THL or JFK. Chaplin had no interest in that kind of accuracy. The fact that Hitler probably never danced with an inflatable globe to Wagner's Lohengrin does not threaten warrant for any emotions in response to The Great Dictator. However these emotions are warranted, then, the mechanism must be different from the mechanism operating in the standard scenario.

Despite its limited scope, the argument does establish that it is possible to warrant emotional carryover from fiction. The significance of this conclusion should not be underestimated. It is not restricted to theories according to which good fiction trains us to respond the right way in the right circumstances, which seem to presuppose that carryover can be appropriate. No one denies that fictions influence our emotions, but relatively little has been said about when this influence is appropriate. Even if it is not the only example of this sort of influence, emotional carryover in the standard scenario is clearly a paradigm case. Establishing the possibility of warrant in this case therefore contributes to the broader project of understanding when and how the emotional influence of fiction is warranted. ${ }^{51}$

\footnotetext{
${ }^{51}$ The scattered footnotes mentioning Paloma Atencia-Linares do not convey the extent of her invaluable assistance in the development and writing of this paper. Nearly every paragraph reflects her contribution, whether in prompting further clarification and elaboration of arguments or in thinking through different puzzles and cases. Many of the virtues of the argument are due to Paloma; the faults are my own. I am grateful to Heythrop College, University of London, for the Research Assistance Grant that made Paloma's contribution possible. Finally, thanks to Tom Crowther for early discussion of various themes in the paper.
} 


\section{REFERENCES}

Broad, C. D. 1954. "Emotion and Sentiment." The Journal of Aesthetics and Art Criticism 13: 203-14. Carnes, Mark C. 1996. "Past Imperfect: History According to the Movies." Interview with Oliver Stone. Cineaste 22: 33-38.

Coplan, Amy. 2006. “Catching Characters' Emotions: Emotional Contagion Responses to Narrative Fiction Film." Film Studies 8: 26-38.

Currie, Gregory. 1990. The Nature of Fiction. Cambridge: Cambridge University Press.

Davies, David. 2001. "Fiction." In The Routledge Companion to Aesthetics, eds. Berys Gaut and

Dominic McIver Lopes. London: Routledge, 263-274.

De Sousa, Ronald. 1987. The Rationality of Emotion, Cambridge, MA: MIT Press.

Ekman, Paul. "Moods, Emotions, and Traits.” In Ekman and Davidson, eds., 56-58.

Ekman, Paul and Davidson, J. Richard, eds. 1994. The Nature of Emotion: Fundamental Questions.

New York: Oxford University Press.

Ekman, Paul, Friesen, Wallace V. and Simons, Ronald C. 1985. "Is the Startle Reaction an Emotion?" Journal of Personality and Social Psychology 49: 1416-1426.

Epstein, Edward J. 1993. “JFK: Oliver Stone's Fictional Reality.” Review of JFK. Atlantic, March, 8994.

Friend, Stacie. 2003. "How I really feel about JFK." In Imagination, Philosophy, and the Arts, eds.

Dominic McIver Lopes and Matthew Kieran. New York: Routledge, 35-53.

. 2006. "Narrating the Truth (More or Less)." In Knowing Art: Essays in Aesthetics and

Epistemology, eds. Dominic McIver Lopes and Matthew Kieran. Dordrecht: Springer, 43-54.

. 2007. "The Pleasures of Documentary Tragedy." British Journal of Aesthetics 47: 184-198.

. 2008. "Imagining Fact and Fiction." In New Waves in Aesthetics, eds. Kathleen Stock and

Katherine Thomson-Jones. Basingstoke: Palgrave Macmillan, 150-169.

Gaut, Berys. 2003. "Reasons, Emotions, and Fictions." In Imagination, Philosophy, and the Arts, eds.

Dominic McIver Lopes and Matthew Kieran. New York: Routledge, 14-34.

2007. Art, Emotion and Ethics. Oxford: Oxford University Press.

Green, Melanie and Timothy C. Brock. 2000. "The Role of Transportation in the Persuasiveness of

Public Narratives." Journal of Personality and Social Psychology 79: 701-721.

. 2002. "In the Mind's Eye: Transportation-Imagery Model of Narrative Persuasion.” In

Narrative Impact: Social and Cognitive Foundations, eds. Melanie C. Green, Jeffrey J. Strange, and Timothy C. Brock, 315-41. Mahwah, NJ: Lawrence Erlbaum.

Greenspan, Patricia. 1988. Emotions and Reasons: an Inquiry into Emotional Justification. New York: Routledge, Chapman and Hall.

Hatfield, Elaine, Cacioppo, John T., and Rapson, Richard L. 1992. Emotional Contagion. Cambridge:

Cambridge University Press.

Hornaday, Ann and Rickhoff, Paul. 2010. "Hurt Locker Takes Flack from Iraq Vets amid Critical

Praise.” Interview by Jeffrey Brown. PBS Newshour, 4 March. Transcript available at

http://www.pbs.org/newshour/bb/entertainment/jan-june10/movies_03-04.html. (Accessed: 20

March 2010).

Lamarque, Peter and Olsen, Stein Haugom. 1994. Truth, Fiction, and Literature. Oxford: Clarendon Press.

Lazarus, Richard S. 1991. Emotion and Adaptation. New York: Oxford University.

LeDoux, Joseph E. 1994. “Cognitive-Emotional Interactions in the Brain.” In Ekman and Davidson, eds., 216-223. 1996. The Emotional Brain: the Mysterious Underpinnings of Emotional Life. New York: 
Simon \& Schuster.

Livingston, Paisley and Mele, Alfred L. 1997. "Evaluating Emotional Responses to Fiction.” In Emotion and the Arts, eds. Mette Hjort and Sue Laver. New York: Oxford University Press, 157-176.

McCormick, Peter. 1985. "Feelings and Fictions." Journal of Aesthetics and Art Criticism 43: 375-383.

Odierno, Ray. 2010. Interview by Jim Lehrer. PBS Newshour, 9 March. Transcript available at http://www.pbs.org/newshour/bb/military/jan-june10/odierno_03-09.html. (Accessed: 20 March 2010).

Paskins, Barrie. 1977. "On being moved by Anna Karenina and Anna Karenina.” Philosophy 52: 344347.

Plantinga, Carl. 1999. "The Scene of Empathy and the Human Face on Film." In Passionate Views, eds. Carl Plantinga and Murray G. Smith. Baltimore: Johns Hopkins University Press, 239-255.

Prentice, Deborah A. and Gerrig, Richard J.1999. "Exploring the Boundary between Fiction and Reality." In Dual-Process Theories in Social Psychology, eds. Shelly Chaiken and Yaacov Trope. New York: Guilford.

Prinz, Jesse J. 2004. Gut Reactions: A Perceptual Theory of the Emotions. New York: Oxford University Press.

Radford, Colin. 1975. "How Can We Be Moved by the Fate of Anna Karenina?" Proceedings of the Aristotelian Society supp. vol. 49: 67-80.

Rieckhoff, Paul. 2010. "When Cinéma Vérité Isn't.” Newsweek. 24 February. Available at http://www.newsweek.com/id/234064. (Accessed: 20 March 2010).

Robinson, Jenefer. 2005. Deeper than Reason: Emotion and its Role in Literature, Music, and Art. Oxford: Oxford University Press.

Rorty, Amélie. 1992. “The Psychology of Aristotelian Tragedy." In Essays on Aristotle’s Poetics, ed. Amélie Rorty. Princeton, NJ: Princeton University Press, 1-22. First published in Midwest Studies in Philosophy 16, Philosophy and the Arts, 53-72.

Walton, Kendall L. 1978. "Fearing Fictions." Journal of Philosophy 75: 5-27. .1990. Mimesis as Make-Believe: On the Foundations of the Representational Arts. Cambridge, MA: Harvard University Press.

Weston, Michael. 1975. "How can we be moved by the fate of Anna Karenina?" Proceedings of the Aristotelian Society supp. vol. 49: 81-93.

Zajonc, Robert. 1980. "Feeling and Thinking: Preferences Need No Inferences." American Psychologist 35: 151-75.

Zillmann, Dolf. 1996. "Sequential Dependencies in Emotional Experience and Behavior." In Emotion: Interdisciplinary Perspectives, eds. Robert D. Kavanaugh, Betty Zimmerberg, and Steven Fein. Mahwah, NJ: Lawrence Erlbaum, 243-72. 